\title{
Predicting the Floods that Follow the Flames
}

Jonathan J. Gourley, Humberto Vergara, Ami Arthur, Robert A. Clark III, Dennis Staley, John Fulton, Laura Hempel, David C. Goodrich, Katherine Rowden, and Peter R. Robichaud

\section{Postwildfire Hydrology Workshop}

What: More than 40 participants, representing government agencies in research, training, and operations; nongovernmental organizations; emergency management; and academia, met for two days in person and online to discuss the monitoring technologies, forecasting tools, and community mitigation efforts in preparation for flash flooding, severe erosion, and debris flows that often follow wildfires.

When: 2-3 October 2019

Where: Norman, Oklahoma

AFFILIATIONS: Gourley - NOAA/OAR/National Severe Storms Laboratory, Norman, Oklahoma; Vergara, Arthur, and Clark - Cooperative Institute for Mesoscale Meteorological Studies, University of Oklahoma, and NOAA/OAR National Severe Storms Laboratory, Norman, Oklahoma; Staley-Landslide Hazards Program, U.S. Geological Survey, Golden, Colorado; Fulton-Colorado Water Science Center, U.S. Geological Survey, Denver, Colorado; Hempel-Colorado Water Science Center, U.S. Geological Survey, Pueblo, Colorado; Goodrich-Agricultural Research Service, U.S. Department of Agriculture, Tucson, Arizona; Rowden-NOAA/National Weather Service/Western Region Headquarters, Salt Lake City, Utah; Robichaud - Rocky Mountain Research Station, U.S. Forest Service, Moscow, Idaho 
he immediate effects of wildfire on a community can be disastrous, as was evident with the Camp Fire in 2018 that burned over 95\% of the structures in

Paradise and Concow, California, and resulted in 85 casualties [one person is still missing to date (15 March 2020)]. But, the secondary effects of wildfire can also have substantial consequences. This was the case in 2017 when the Thomas Fire raged in Santa Barbara and Ventura Counties in Southern California, eventually burning $1,141 \mathrm{~km}^{2}$ of landscape. Before the wildfire was 100\% contained, a storm system moved over the mountainous terrain above Montecito, California, and produced rainfall rates that triggered deadly debris flows that traveled down the canyons to the Pacific Ocean. Twenty-one people lost their lives [two are still missing to date (15 March 2020)] and more than 400 structures were destroyed or damaged (Kean et al. 2019). These tragic events are expected to become more costly to lives and infrastructure with forest fires becoming more numerous, larger, and longer lasting (Westerling et al. 2006; Miller et al. 2009; Dennison et al. 2014).

The onset and severity of flash floods, severe erosion, and debris flows emanating from burned landscapes depend on numerous factors that cross scientific disciplines and governmental jurisdictions. The federal and local government agencies often conduct postfire assessments; however, their associated funds for mitigation do not often cross these jurisdictional boundaries, leaving the collaboration and information sharing up to scientists, local governments, community efforts, and local citizen scientists. For these reasons, a workshop was organized to bring together a sample of scientists, operational forecasters, emergency managers, and nongovernmental agencies involved in mitigation efforts; all of whom have an interest in improving society's ability to become more resilient to flash floods, severe erosion, and debris flows following wildfire.

There is a wide range of postwildfire preparedness and mitigation activities that can and often do take place on the hillslopes, in the channels, and within the communities themselves. The physical mitigation efforts are guided by hydrologic models that account for changes in erosion, sediment delivery, and runoff in response to wildfire disturbances to the soil properties and overlying vegetation(Robichaud and Ashmun 2013). The workshop focused more on the modeling, alerting, and public warning of hydrologic responses given forecasts or estimates of rainfall in real time rather than using design rainstorms for planning purposes. The overarching goal of the workshop was to develop a dialogue among the partners to share tools and techniques for forecasting flash floods, severe erosion, and debris flows in response to intense rainfall, to highlight research and development needs for improving prediction, and to identify both short- and long-term methodologies that can be considered for transitioning to operational weather forecasting centers.

\section{Format of the workshop}

The workshop began with a morning session focused on user perspectives, spanning a wide range of effects from large-scale sedimentation on reservoirs to local flooding in a community. Each speaker had 30 min to describe the challenges they face when confronted with an impending disaster on burn areas within their areas of responsibility. These topics included forecast challenges in an operational weather and river forecasting environment, mitigation, community preparedness, alerting at a local level, and recovery. Time was allotted for discussions, which were numerous and productive. The second afternoon session focused on monitoring technologies and included five presentations on weather radar-based methodologies for estimating rainfall rates that trigger floods, severe erosion, and debris flows, contemporary radar measurements in streams, and satellite-based observations to quantify soil burn severity, spatial extent, and recovery. The third session the following day highlighted models used for postfire simulation of runoff, erosion, and sedimentation. 


\section{Outcomes}

A challenging problem for operational forecasting systems. There are confounding factors with forecasting hydrologic responses on burn areas using conventional methods, tools, and models. First, some of the biggest and most damaging wildfires occur in forested, mountainous terrain. This complex terrain poses substantial challenges to the operational numerical weather prediction models for forecasting rainfall and to in situ sensors and remote sensing methods for estimating the spatial patterns and magnitudes of rainfall (Maddox et al. 2002; Lundquist et al. 2019). Inaccurate rainfall forecasting and estimation by the operational models and networks, respectively, limits the ability of National Weather Service forecasters to recognize potentially dangerous situations and issue warnings to the local communities. Presently, forecasters depend on rain gauge networks to detect flash flood-producing or debris-flow-producing rainfall rates, but the short time between the concomitant rainfall and resulting hydrologic responses prevents lead time for alerting the public and providing them adequate time to respond.

Even if the rainfall rates can be accurately estimated or forecast, the magnitude of the hydrologic response on a burn area to rainfall depends on several factors including the spatial distribution of the soil burn severity. The standard approach for monitoring the intensity and duration of rainfall rates that may trigger debris flows on burn areas utilizes a logistic regression (Staley et al. 2017). One of the variables involved is the soil burn severity, which is provided by a Burn Area Emergency Response (BAER) team who field validates the burned area reflectance classification (BARC) imagery (Parsons et al. 2010). The soil burn severity classification is obtained following a field survey requiring resources and time following containment of the wildfire (Parsons et al. 2010). In some cases, there can be a threat of heavy rainfall on a burn area before the wildfire is fully contained, which limits the accuracy of the methods employed to derive the rainfall rates that are anticipated to trigger debris flows. Last, the approach described herein is for rainfall intensity-duration curves that trigger debris flows, and do not readily apply to flash floods.

Role of remote sensing. An emerging theme for the prediction and monitoring of hydrologic responses on burn areas was the use of remote sensing systems. From space, imagery from sensors on board low-Earth-orbiting platforms (i.e., Landsat, MODIS, ASTER, SPOT) can be used to detect the condition of vegetation in the visible, near-infrared, and shortwave-infrared bands (Hudak et al. 2007). These data are used to derive useful metrics for classifying the disturbance to the vegetation and then assigning burn severity indices. There are limitations to the approaches, such as spatial resolution, satellite revisit time, and lack of correlation to soil properties, which requires field validation. Several presentations highlighted needs for assessing how and when a basin has recovered following wildfire (Lewis et al. 2017). Recovery is an area requiring more attention by the research community as it is a function of burn severity, presence of seed sources, and postfire precipitation to germinate and grow new ground cover, especially in water-limited environments.

Remote sensing from active sensors placed above streams provides new capabilities for quantifying hydrologic responses on burn areas and alerting local stakeholders(Fulton et al. 2020).. Commercially available sensors have been deployed to burn areas and provide real-time data on stage and surface velocity. If the stream cross section is known through a survey or other methods, then these data can be used to provide real-time estimates of stream discharge. Data recording and transmission times are adaptable to conditions, enabling alerts to be transmitted by Short Message Service (SMS) in real time. The Spring Creek burn area in southeast Colorado was highlighted as a particularly densely instrumented basin with 10 rain gauges, 8 stage sensors, 11 surface velocity sensors, and 3 soil moisture sensors, all placed within and downstream from the $437-\mathrm{km}^{2}$ burn area. Initial results from 
this pilot project showed surface velocities as high as $5 \mathrm{~m} \mathrm{~s}^{-1}$ that responded to collocated rainfall within $4 \mathrm{~min}$. Although this short time is limiting, the data and associated alerting capabilities are useful for focusing community response efforts to specific streams and downstream effects from a burn area.

Additional lead time can be offered through weather radar observations near the burn area. Beam blockages by intervening terrain and large distances from operational weather radars, a common occurrence in the Intermountain West, limits conventional radar-based flash flood, severe erosion, and debris-flow alerting capabilities. In some cases, smaller-wavelength radars from mobile platforms are deployed to burn areas for enhanced monitoring for ranges up to $150 \mathrm{~km}$. Although data from these mobile platforms do not have the same high quality as the operational weather radar networks, they can be rapidly deployed in operational radar gaps with real-time data transmission capabilities to local National Weather Service offices and local communities. Further, mobile weather radars offer flexibility in scanning strategies to focus on vulnerable areas at high spatiotemporal resolution, which is useful for both real-time monitoring and research studies.

Varied hydrologic models in terms of platforms, uses, and physical descriptions. Several hydrologic models employed for targeting postfire treatments and risk assessments (Robichaud and Ashmun 2013; Goodrich et al. 2012; Staley et al. 2017)erosion, sediment delivery, debrisflow runout, inundation extent, and/or hillslope and channel runoff in response to rainfall on burned landscapes. The standard practice is to use design rainstorms as inputs to the models. Others use a probability approach based on numerous model runs of physically based models (Robichaud et al. 2007). One outcome was identifying the need for developing a library of radar-based rainfall datasets on prior flash flood, severe erosion, and debris-flow events to provide a more realistic depiction of the spatial and temporal distribution of precipitation rather than a basin-aggregated analysis. The design of the presented models varied in terms of hosted platforms, applications, and physical descriptions of the soils, vegetation, landscapes, and geomorphology. These differences are primarily driven by local user and federal agency needs. There have been some limited efforts to forcing these models with radar-based rainfall to provide real-time responses. As with soil burn severity assessments, however, there is a need for field surveys to determine channel cross sections and to determine the flood stages corresponding to bank-full conditions.

A call to action. Scientific progress was reviewed in relation to the findings and recommendations of the joint National Oceanic and Atmospheric Administration (NOAA)-U.S. Geological Survey (USGS) Task Force that addressed precipitation forecasting and debris-flow hazard assessments (NOAA-USGS Debris Flow Task Force 2005). The near-term goals (i.e., 2-5 years) of demonstrating a debris-flow warning system in Southern California on recently burned areas and then expanding to all burn areas in the West have been accomplished. The National Weather Service regularly updates the flash flood guidance thresholds in the Flash Flood Monitoring and Prediction (FFMP) software to reflect the latest USGS-published thresholds for triggering debris flows. The additional near-term goal of the report called for a national debrisflow warning system to operate in areas not burned by wildfire to develop regionally specific rainfall intensity-duration thresholds and to map areas of high slope instability. Inundation maps would be produced for these areas over a range of debris-flow volumes. This goal has not been fully met, although there has been recent progress on the topic (Staley et al. 2018).

The longer-term goals of the report (i.e., 5-10 years) called for a coupled system that connects numerical weather prediction model forecasts and radar observations of spatially distributed rainfall to hydrologic models with soil moisture accounting that would then be coupled to highresolution slope-stability models. Since the release of the report, our physical understanding 
of processes that trigger debris flows has improved. While soil moisture conditions potentially impact the volume and velocity of debris flows, initially wet soils do not necessarily influence the likelihood of triggering debris flows (Iverson et al. 2011). Furthermore, observations of debris flows have revealed that triggering mechanisms were associated with severe runoff generation and erosion rather than slope failure. Last, there are opportunities to improve models so that they can guide the treatment of fuels prefire so as to reduce the burn severity and thus mitigate postfire flash flooding, severe erosion, and debris flows. As such, these longer-term goals should be revised based on recent findings.

There has also been great progress in the role of remote sensing from space and from sensors placed in close proximity to streams. These contemporary observations of in-stream velocity and stage, rainfall by in situ rain gauges and mobile weather radars, and soil moisture sensors should be considered in future network designs on burn areas. This combined observational and modeling framework could provide real-time information on when and where debris flows were likely to occur, forecast their volumes, and map the anticipated inundated area. This longer-term goal set out in 2005 remains unmet 15 years following publication of the report. The report concludes by stating that the financial resources required to support an operational system are beyond the capabilities of either agency (i.e., USGS or NOAA), and a long-term commitment of resources from both agencies would be needed for successful implementation of the nationwide debris-flow warning system. Although the report was specific to the USGS and NOAA, the effects of postwildfire flooding, severe erosion, and debris flows affect additional federal agencies including but not limited to the U.S. Forest Service, U.S. Department of the Interior, U.S. Department of Agriculture, National Aeronautics and Space Administration, U.S. Army Corps of Engineers, and U.S. Environmental Protection Agency.

Postwildfire hydrologic responses cross multiple scientific disciplines and affect several government agencies. Perhaps as a result, there is no single program designed to unite the scientific community and coordinate research efforts targeting the common goal of reducing the effects of postwildfire flash flooding, severe erosion, and debris flows on local communities. Complex terrain challenges operational observing and forecasting systems. Wildfires are increasing in size, duration, and magnitude, while communities continue to develop in proximity to forests extending the wildland-urban interface. All these factors point to a future with potentially more devastating and frequent flash floods, severe erosion, and debris flows following wildfire.

Acknowledgments. Funding for the 2019 Postwildfire Hydrology Workshop was provided by the Cooperative Institute for Mesoscale Meteorological Studies at the University of Oklahoma, under the discretion of the director, Dr. Greg McFarquhar. CIMMS provided travel support for several of the participants from academic institutions. We are grateful for those participants from federal agencies who attended on their own travel budgets. Funding was provided by NOAA/Office of Oceanic and Atmospheric Research under NOAA-University of Oklahoma Cooperative Agreement \#NA11OAR4320072, U.S. Department of Commerce. Any use of trade, firm, or product names is for descriptive purposes only and does not imply endorsement by the U.S. Government. 


\section{References}

Dennison, P. E., S. C. Brewer, J. D. Arnold, and M. A. Moritz, 2014: Large wildfire trends in the western United States, 1984-2011. Geophys. Res. Lett., 41, 2928-2933, https://doi.org/10.1002/2014GL059576.

Fulton, J., and Coauthors, 2020: Near-field remote sensing of surface velocity and river discharge using radars and the probability concept at 10 U.S. Geological Survey streamgages. Remote Sens., 12, 1-28, https://doi.org/10.3390/ rs12081296.

Goodrich, D. C., and Coauthors, 2012: KINEROS2/AGWA: Model use, calibration, and validation. Trans. ASABE, 55, 1561-1574, https://doi. org/10.13031/2013.42264.

Hudak, A. T., and Coauthors, 2007: The relationship of multispectral satellite imagery to immediate fire effects. Fire Ecol., 3, 64-90, https://doi.org/10.4996/ fireecology. 0301064.

Iverson, R. M., M. E. Reid, M. Logan, R. G. LaHusen, J. W. Godt, and J. P. Griswold, 2011: Positive feedback and momentum growth during debris-flow entrainment of wet bed sediment. Nat. Geosci., 4, 116-121, https://doi.org/10.1038/ ngeo1040.

Kean, J. W., and Coauthors, 2019: Inundation, flow dynamics, and damage in the 9 January 2018 Montecito debris-flow event, California, USA: Opportunities and challenges for post-wildfire risk assessment. Geosphere, 15, 1140-1163, https://doi.org/10.1130/GES02048.1.

Lewis, S. A., and Coauthors, 2017: Indicators of burn severity at extended temporal scales: A decade of ecosystem response in mixed-conifer forests of western Montana. Int. J. Wildland Fire, 26, 755-771, https://doi.org/10.1071/ WF17019.

Lundquist, J., M. Hughes, E. Gutmann, and S. Kapnick, 2019: Our skill in modeling mountain rain and snow is bypassing the skill of our observational networks. Bull. Amer. Meteor. Soc., 100, 2473-2490, https://doi.org/10.1175/BAMSD-19-0001.1.

Maddox, R. A., J. Zhang, J. J. Gourley, and K. W. Howard, 2002: Weather radar coverage over the contiguous United States. Wea. Forecasting, 17, 927-934, https://doi.org/10.1175/1520-0434(2002)017<0927:WRCOTC>2.0.C0;2.
Miller, J., H. Safford, M. Crimmins, and A. Thode, 2009: Quantitative evidence for increasing forest fire severity in the Sierra Nevada and Southern Cascade Mountains, California and Nevada, USA. Ecosystems, 12, 16-32, https://doi. org/10.1007/s10021-008-9201-9.

NOAA-USGS Debris Flow Task Force, 2005: NOAA-USGS debris-flow warning system—Final report. USGS Circular 1283, 47 pp., https://pubs.usgs.gov/ circ/2005/1283/pdf/Circular1283.pdf.

Parsons, A., P. R. Robichaud, S. A. Lewis, C. Napper, and J. T. Clark, 2010: Field guide for mapping post-fire soil burn severity. Dept. of Agriculture Forest Service Tech. Rep. RMRS-GTR-243, 49 pp., www.fs.fed.us/rm/pubs/rmrs_gtr243. pdf.

Robichaud, P. R., and L. E. Ashmun, 2013: Tools to aid post-wildfire assessment and erosion-mitigation treatment decisions. Int. J. Wildland Fire, 22, 95-105, https://doi.org/10.1071/WF11162.

— W. J. Elliot, F. B. Pierson, D. E. Hall, and C. A. Moffet, 2007: Predicting postfire erosion and mitigation effectiveness with a web-based probabilistic erosion model. Catena, 71, 229-241, https://doi.org/10.1016/j.catena.2007.03.003.

Staley, D. M., J. A. Negri, J. W. Kean, J. L. Laber, A. C. Tillery, and A. M. Youberg, 2017: Prediction of spatially explicit rainfall intensity-duration thresholds for post-fire debris-flow generation in the western United States. Geomorphology, 278, 149-162, https://doi.org/10.1016/j.geomorph.2016.10.019.

, A. C. Tillery, J. W. Kean, L. A. McGuire, H. E. Pauling, F. K. Rengers, and J. B. Smith, 2018: Estimating post-fire debris-flow hazards prior to wildfire using a statistical analysis of historical distributions of fire severity from remote sensing data. Int. J. Wildland Fire, 27, 595-608, https://doi.org/10.1071/WF17122.

Westerling, A. L., H. G. Hidalgo, D. R. Cayan, and T. W. Swetnam, 2006: Warming and earlier spring increase western US forest wildfire activity. Science, 313, 940-943, https://doi.org/10.1126/science.1128834. 